\title{
Implementasi Metodologi Prototyping Dalam Perancangan Sistem Informasi Pencatatan Referral Pada PT Bank Central Asia Tbk Berbasis Android
}

\author{
Doni $^{*}$, Riyadi Jimmy Iskandar ${ }^{2}$ \\ ${ }^{1}$ Program Studi Sistem Informasi, Fakultas Teknologi Informasi, Universitas Widya Dharma Pontianak \\ ${ }^{2}$ Program Studi Informatika, Fakultas Teknologi Informasi, Universitas Widya Dharma Pontianak \\ *doni@widyadharma.ac.id
}

\begin{abstract}
Referral is the process of recording the data of someone who has been invited to buy or sell a product that has been offered by a company. Data recording carried out by Bank BCA Ayani Pontianak still uses a manual recording system using paper or google forms. This makes the recording process longer; this problem causes time and cost losses to the company. To increase efficiency and flexibility which can make record keeping easier. Bank $B C A$ needs to implement a recording system using an android-based recording application. This application also has flexibility, so that employees of Bank BCA can use this application anywhere and anytime. This is indicated by $93 \%$ of respondents agree. Black box testing of the system when it is executed also shows the success of the application when it is run. The application of the prototyping methodology also provides an overview to the user of how the application will be developed. From the tests carried out, the authors can make improvements to the quality of the application.
\end{abstract}

Keywords: prototyping, design, information system, based on android

\begin{abstract}
Abstrak
Referral merupakan proses pencatatan data seseorang yang telah diajak untuk membeli maupun menjual suatu produk yang telah ditawarkan oleh suatu perusahaan. Pencatatan data yang dilakukan oleh Bank BCA Ayani Pontianak masih menggunakan sistem pencatatan secara manual dengan menggunakan kertas ataupun google form. Hal ini membuat proses pencatatan menjadi semakin lama, permasalahan ini menyebabkan kerugian waktu dan biaya kepada pihak perusahaan. Untuk meningkatkan efisiensi dan fleksibilitas yang dapat membuat pencatatan menjadi lebih mudah. Maka Bank BCA perlu menerapkan sistem pencatatan dengan menggunakan aplikasi pencatatan berbasis android. Aplikasi ini juga memiliki fleksibilitas, sehingga para karyawan Bank BCA bisa menggunakan aplikasi ini dimanapun dan kapanpun. Hal ini ditunjukan oleh $93 \%$ responden menyatakan setuju. Pengujian black box terhadap sistem saat dieksekusi juga menunjukkan keberhasilan aplikasi saat dijalankan. Penerapan metodologi prototyping juga memberikan gambaran kepada pengguna bagiamana aplikasi akan dikembangkan. Dari pengujian yang dilakukan, penulis dapat melakukan peningkatan terhadap kualitas aplikasi.
\end{abstract}

Kata kunci: prototyping, perancangan, sistem informasi, berbasis android

\section{Pendahuluan}

Informasi bagi sebuah organisasi adalah aset yang sangat berharga. Informasi yang berkualitas dapat menjadi masukkan bagi organisasi dalam menentukan langkah serta strategi dalam menjalakan proses bisnis. Informasi berkualitas jika memenuhi unsur akurat, tepat waktu dan relevan bagi penggunanya. Informasi merupakan aset yang harus dijaga oleh organisasi, karena pentingnya sebuah informasi.

Referral merupakan proses pencatatan data seseorang yang telah diajak untuk membeli maupun menjual suatu produk yang telah ditawarkan oleh suatu perusahaan. Proses pencatatan data dapat dilakukan secara manual (tulis tangan) dan juga dapat dilakukan secara digital yang disebut sebagai 
pemanfaatan teknologi tidak berwujud. Dalam pencatatan data, perlu adanya sistem yang dapat menyajikan efisiensi dan fleksibilitas dalam proses memasukkan data dan mengambil data, penggunaan sistem yang telah terkomputerisasi merupakan hal yang baik dalam pengolahan data yang dapat menghasilkan kenyamanan dan mudah digunakan oleh karyawan-karyawan.

Pencatatan data yang dilakukan oleh Bank BCA Ayani Pontianak masih menggunakan sistem pencatatan secara manual dengan menggunakan kertas ataupun google form. Hal ini membuat proses pencatatan menjadi semakin lama, permasalahan ini menyebabkan kerugian waktu dan biaya kepada pihak perusahaan. Pencatatan manual juga membuat pihak bank membutuhkan waktu yang panjang dalam mengolah data menjadi informasi dalam mengambil keputusan. Informasi dari pencatatan referral merupakan data primer bagi Bank BCA dalam mengembangkan kegiatan bisnisnya.

Berdasarkan dari hasil analisis penulis, salah satu cara untuk mendukung proses pencatatan data di Bank BCA perlu adanya suatu sistem baru untuk memudahkan proses pencatatan. Untuk meningkatkan efisiensi dan fleksibilitas yang dapat membuat pencatatan menjadi lebih mudah. Maka Bank BCA perlu menerapkan sistem pencatatan dengan menggunakan aplikasi pencatatan berbasis android.

Pemilihan aplikasi berbasis android ini dikarenakan aplikasi berbasis android dapat digunakan di manapun dan kapanpun di smartphone yang dapat dikatakan bahwa semua orang telah memiliki smartphone, sehingga proses pencatatan data pun menjadi semakin mudah dan cepat. aplikasi pencatatan ini diharapkan dapat membantu proses pencatatan data menjadi semakin fleksibel dan efisien secara terkomputerisasi sehingga diperoleh hasil pencatatan data yang cepat dan mudah dimanapun dan kapanpun.

\section{Metoda Penelitian}

Menurut Lubis (2016), "Data adalah fakta-fakta yang menggambarkan suatu kejadian yang sebenarnya pada waktu tertentu, data didapat dari data suatu perusahaan, data transaksi, dll. Data dapat diidentikkan dengan laporan tertulis" [1].

Menurut Wijoyo, et al (2021), "Informasi adalah data yang diolah menjadi bentuk yang lebih berguna dan lebih berarti bagi yang menerimanya" [2].

Menurut Kristanto (2008) "Analisis sistem adalah seseorang yang mempunyai kemampuan untuk menganalisa sebuah sistem. Analisa tersebut meliputi mempelajari masalah-masalah yang timbul dan menentukan kebutuhan-kebutuhan pemakai sistem" [3].

Prototype sistem aplikasi dapat meningkatkan proses pengaturan penjadwalan kalibrasi secara berkala dan dapat memudahkan bagian produksi dalam mengolah dan menyediakan informasi mengenai inventory alat produksi [4].

Menurut Rianto (2021), "UML adalah bahasa berorientasi objek untuk menentukan, memvisualisasikan, membangun, dan mendokumentasikan artefak sistem perangkat lunak, serta untuk pemodelan bisnis" [5].

\section{Hasil Penelitian}

\subsection{Analisis Sistem Berjalan}

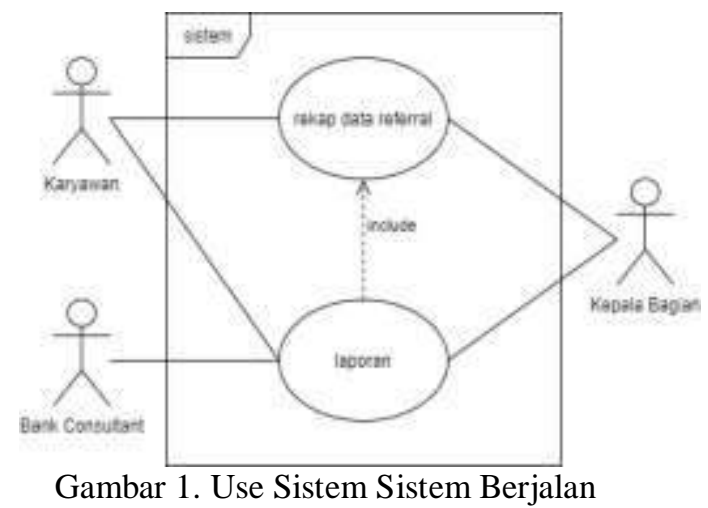

Proses pencatatan data referral akan dimulai dari karyawan mencatat atau merekap data referral dan kemudian data-data yang telah dikumpulkan akan diserahkan kepada kepala bagian. Kepala bagian akan mengumpulkan data-data tersebut dan melakukan verifikasi ulang pada data yang telah terkumpul kemudian akan menyerahkan data tersebut kepada bank consultant. Bank consultant akan menerima data referral tersebut dari kepala bagian dan akan segera mem-follow up nasabah tersebut dan 
kemudian bank consultant akan membuat laporan mengenai hasil follow up tersebut.

Proses prosedur laporan dimulai dari bank consultant yang membuat laporan dan kemudian laporan tersebut akan didistribusikan kepada kepala bagian. Kepala bagian akan mendistribusikan laporan tersebut kepada karyawan. Laporan tersebut digunakan untuk mengambil keputusan dalam pemberian bonus untuk karyawan yang banyak tercatat dalam data referral.

\subsection{Analisis Kebutuhan Fungsional}

Melalui metode observasi dan wawancara terhadap kegiatan pencatatan data referral pada Bank BCA, terdapat beberapa kebutuhan fungsional sistem. Beberapa kebutuhan fungsional yang menjawab kebutuhan sistem sebagai berikut:

1. Sistem dapat membedakan user yang mengisi data referral.

2. Sistem dapat memproses data referral yang diinput oleh karyawan.

3. Sistem dapat memproses data referral yang diinput karywan oleh bank consultant.

4. Sistem dapat memberikan informasi kepada karyawan terkait data referral yang diinput.

5. Sistem dapat menampilkan history data referral.

6. Sistem dapat menampilkan progres dari setiap data referral yang diinput.

7. Sistem dapat memberikan tanda untuk data yang telah di follow up oleh kepala bagian.

\subsection{Analisis Kebutuhan Nonfungsional}

Kebutuhan nonfungsional berdasarkan hasil analisis untuk menjawab kebutuhan sistem adalah sebagai berikut:

1. Sistem dapat berjalan dengan spesifikasi minimal android versi ice dream sandwich.

2. Ukuran perangkat android bersifat relative sehingga dapat digunakan pada perangkat tablet.

3. Sistem dapat mengenali jenjang user saat login.

\subsection{Rancangan Sistem Usulan}

Perancangan sistem usulan yang telah direncanakan untuk Bank BCA merupakan suatu sistem terkomputerisasi, yaitu dari sistem manual menjadi sistem berbasis android yang dibuat berdasarkan hasil analisis pada sistem berjalan pada saat ini. Dengan adanya sistem terkomputerisasi ini, diharapkan dapat mempermudah proses pencatatan data referral, dan mempermudah proses pembuatan laporan yang lebih terstruktur. Sistem usulan berbasis android juga akan memudahkan karyawan karena dapat diakses kapanpun dan di manapun.

Diagram use case akan menggambarkan fungsionalitas dari sistem pencatatan data referral berbasis android yang penulis usulkan. Adapun proses sistem usulan sebagai berikut:

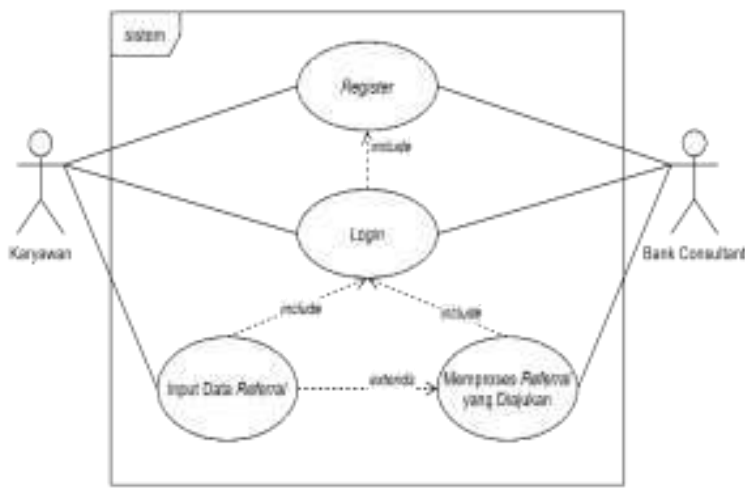

Gambar 2. Use Case Sistem Usulan

Proses pencatatan referral akan dimulai dari user (karyawan / bank consultant) login . Jika user (karyawan / bank consultant) memasukkan email dan password yang benar, maka user (karyawan / bank consultant) akan dapat login. Namun jika user (karyawan / bank consultant) belum memiliki akun, maka user (karyawan / bank consultant) dapat mendaftarkan akun baru melalui aplikasi ini pada saat itu juga. Jika karyawan sudah login, maka karyawan dapat melakukan input data referral, dan melihat status referral. Jika bank consultant sudah login, maka bank consultant dapat memproses referral yang diajukan oleh karyawan.

Proses input referral yang diusulkan penulis pada sistem usulan dalam diagram sekuensial input data di bawah menceritakan proses pencatatan data referral yang dimulai dari user memilih jenis referral yang ingin diinput, kemudian aplikasi akan memunculkan form penginputan data referral, kemudian user akan memasukkan data referral, kemudian aplikasi akan memvalidasi data tersebut. Jika sudah sesuai 
maka data tersebut akan dimasukkan ke database. Setelah masuk ke database, data tersebut akan tampil pada form pending, dan jika gagal maka akan kembali ke form penginputan.

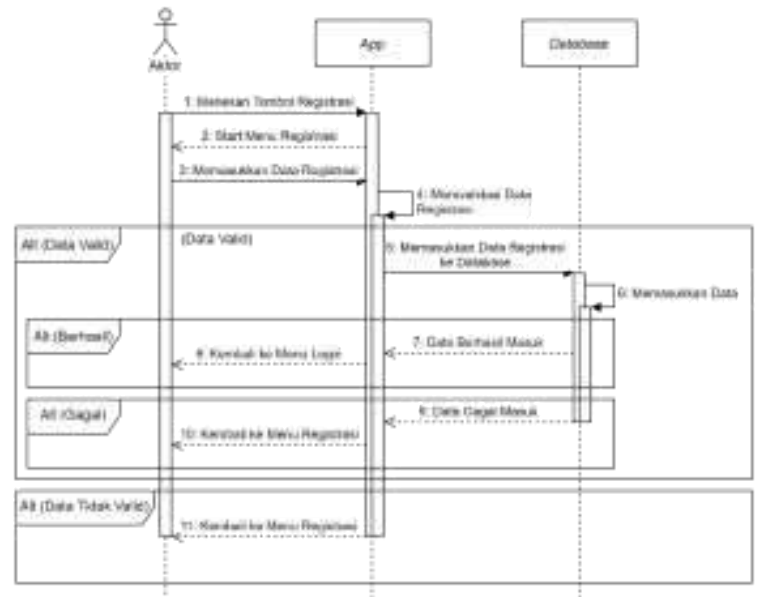

Gambar 3. Diagram Sekuensial Input Referral

Proses follow-up yang diusulkan pada sistem usulan digambarkan dalam diagram sekuensial follow-up di bawah dimulai dari user (bank consultant) memilih referral yang berstatus pending. Setelah aplikasi mengambil data dari database dan menampilkan data referral tersebut kepada bank consultant, bank consultant dapat melakukan follow-up kepada nasabah tersebut.

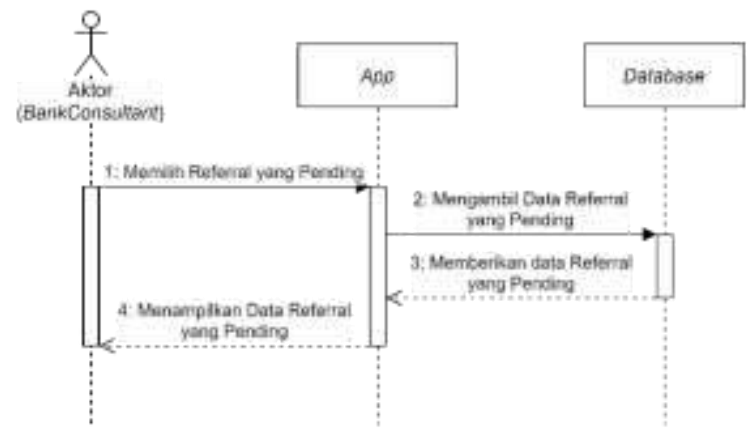

Gambar 4. Diagram Sekuensial Follow-Up

\subsection{Rancangan Input}

Perancangan dan tampilan form input sistem informasi pada aplikasi pencatatan referral Bank BCA adalah sebagai berikut:
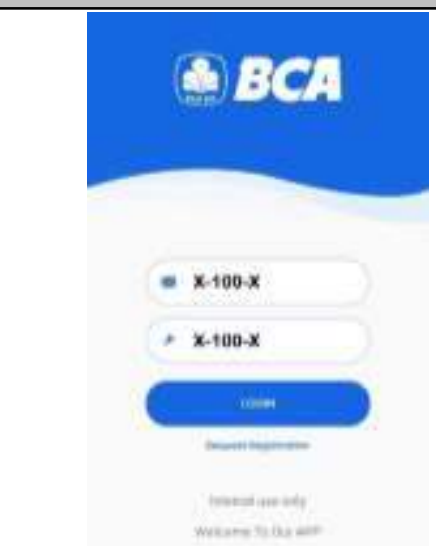

Gambar 5. Rancangan Form Login
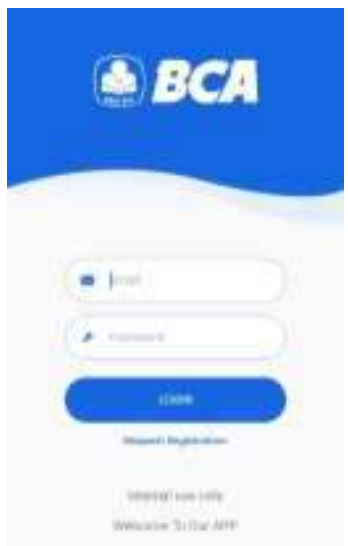

Gambar 6. Tampilan Form Login

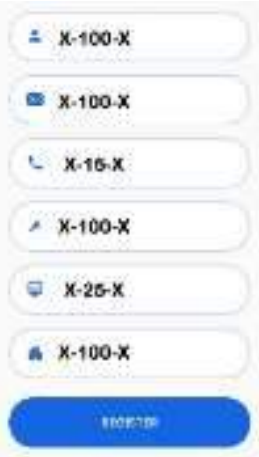

Gambar 7. Rancangan Registrasi Bank Consultant

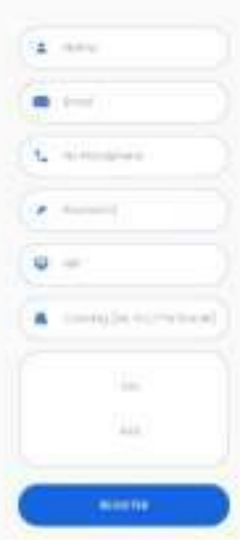

Gambar 8. Tampilan Registrasi Bank Consultant 


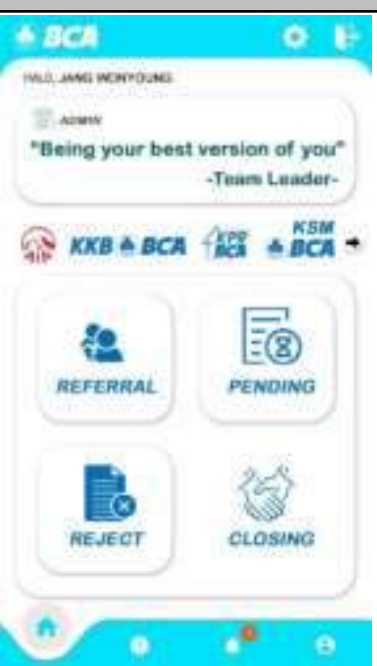

Gambar 9. Tampilan Menu Utama

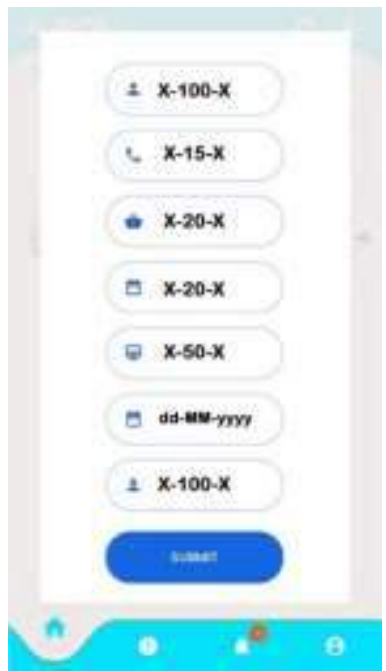

Gambar 10. Rancangan Form Referral

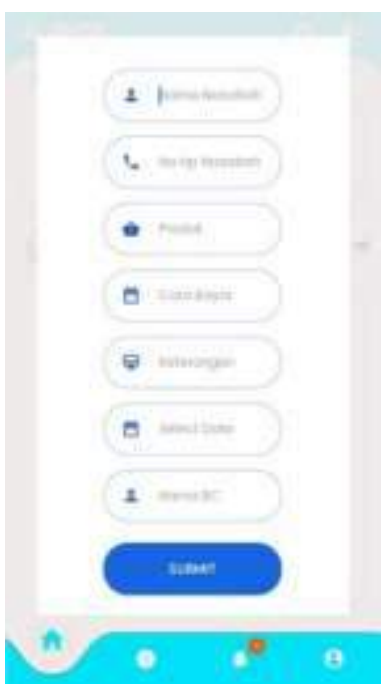

Gambar 11. Tampilan Form Referral
3.6. Rancangan Output

Tampilan form output berupa tangkapan layar pada aplikasi pencatatan referral Bank BCA adalah sebagai berikut:

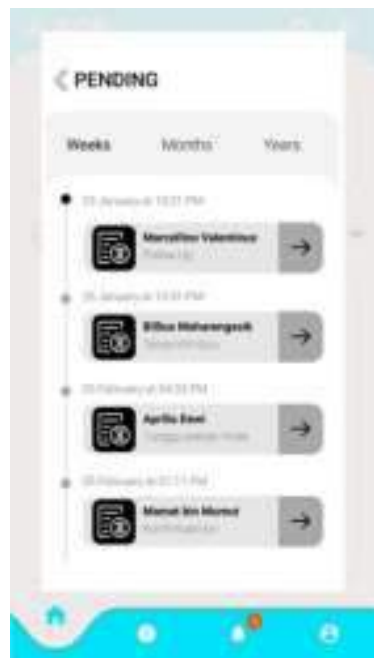

Gambar 12. Tampilan Laporan Pending

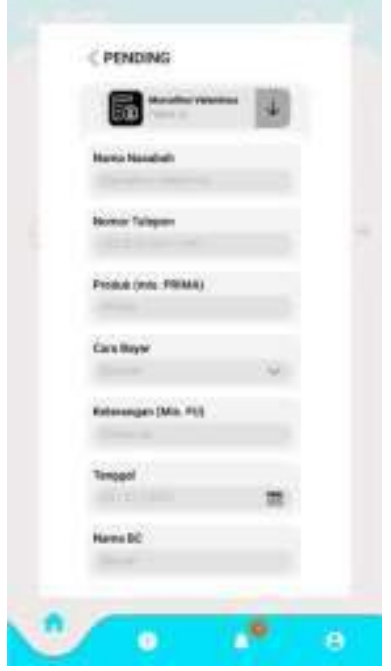

Gambar 13. Tampilan Detail Laporan Pending

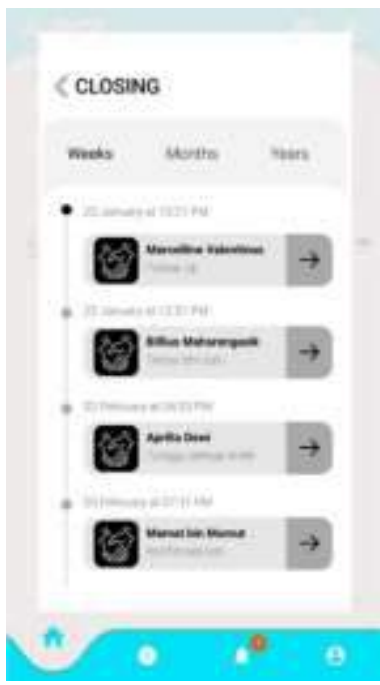

Gambar 14. Laporan Closing 
\REJECT

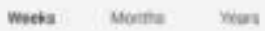

\section{D}

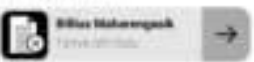

D
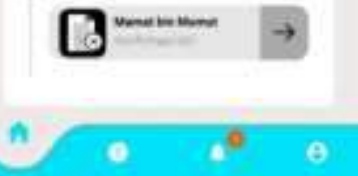

Gambar 15. Tampilan Laporan Reject

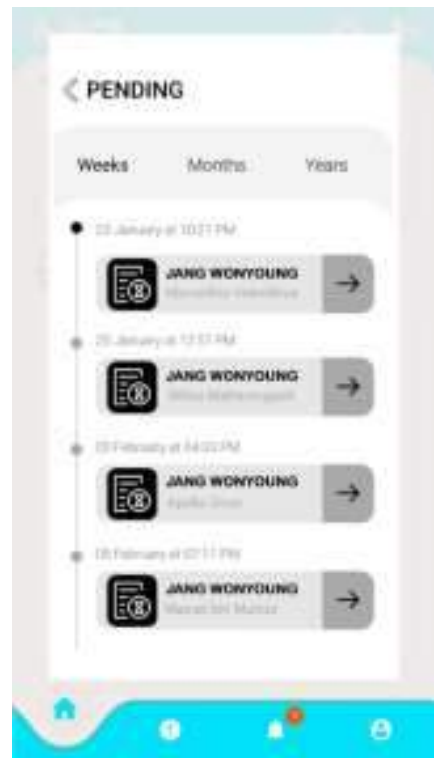

Gambar 16. Tampilan Laporan Pending Bank Consultant

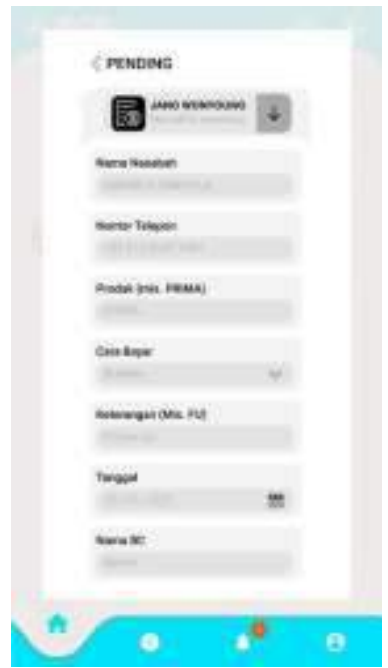

Gambar 17. Tampilan Laporan Detail Pending Bank Consultant

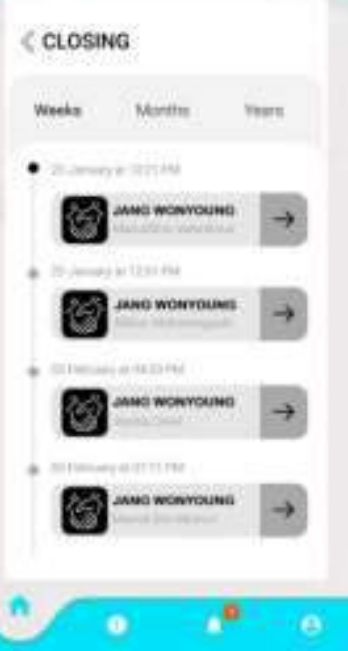

Gambar 18. Tampilan Laporan Closing Bank Consultant

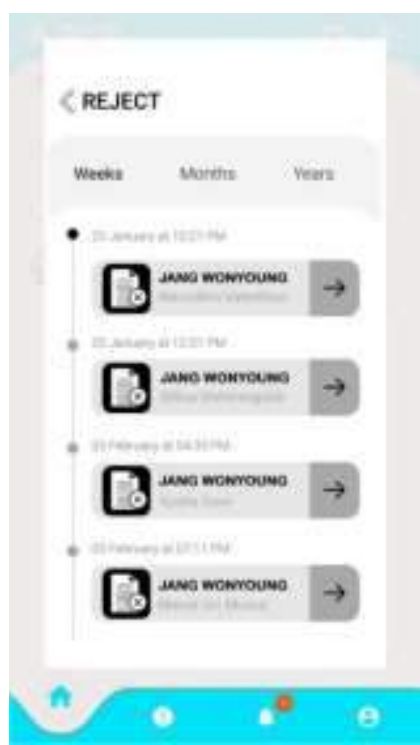

Gambar 19. Tampilan Laporan Reject Bank Consultant

\subsection{Hasil Pengujian}

Pengujian yang dilakukan terhadap sistem informasi pencatatan data referral adalah pengujian black box dan menyebarkan kuesioner kepada karyawan Bank BCA cabang Ayani Pontianak. Berikut merupakan hasil pengujian black box terhadap sistem informasi pencatatan data referral:

Tabel 1 Pengujian Black Box

\begin{tabular}{|c|c|c|c|c|}
\hline No & Kasus & Skenario Uji & Hasil yang diharapkan & $\begin{array}{c}\text { Hasil } \\
\text { Pengujian }\end{array}$ \\
\hline 1 & $\begin{array}{l}\text { Menginstal } \\
\text { Aplikasi } \\
\text { pada } \\
\text { perangkat } \\
\text { Android }\end{array}$ & $\begin{array}{l}\text { Memilih tombol } \\
\text { instal saat } \\
\text { aplikasi } \\
\text { dijalankan }\end{array}$ & $\begin{array}{l}\text { Aplikasi pencatatan data } \\
\text { referral berhasil dipasang } \\
\text { di gadget }\end{array}$ & $\begin{array}{l}\square \text { Berhasil } \\
\square \text { Gagal }\end{array}$ \\
\hline 2 & $\begin{array}{l}\text { Daftar } \\
\text { Akun } \\
\text { Karyawan }\end{array}$ & $\begin{array}{l}\text { Memilih } \\
\text { pendaftaran } \\
\text { akun sebagai } \\
\text { karyawan }\end{array}$ & $\begin{array}{l}\text { Dapat melakukan infput } \\
\text { data sebagai karyawan } \\
\text { dan memiliki akses } \\
\text { masuk berupa email dan } \\
\text { password }\end{array}$ & $\begin{array}{l}\square \text { Berhasil } \\
\square \text { Gagal }\end{array}$ \\
\hline
\end{tabular}




\begin{tabular}{|c|c|c|c|c|}
\hline \multicolumn{5}{|c|}{ METIK VOLUME. 5 NOMOR. 22021} \\
\hline No & Kasus & Skenario Uji & Hasil yang diharapkan & $\begin{array}{c}\text { Hasil } \\
\text { Pengujian }\end{array}$ \\
\hline 3 & $\begin{array}{l}\text { Daftar } \\
\text { Akun Bank } \\
\text { Consultant }\end{array}$ & $\begin{array}{l}\text { Memilih } \\
\text { pendaftaran } \\
\text { akun sebagai } \\
\text { Bank } \\
\text { Consultant }\end{array}$ & $\begin{array}{l}\text { Dapat melakukan infput } \\
\text { data sebagai karyawan } \\
\text { dan memiliki akses } \\
\text { masuk berupa email dan } \\
\text { password }\end{array}$ & $\begin{array}{l}\square \text { Berhasil } \\
\square \text { Gagal }\end{array}$ \\
\hline 4 & $\begin{array}{l}\text { Mengisi } \\
\text { form } \\
\text { referral }\end{array}$ & $\begin{array}{l}\text { Menginputkan } \\
\text { data pada form } \\
\text { referral setalh } \\
\text { melakukan } \\
\text { login }\end{array}$ & $\begin{array}{l}\text { Dapat mengisi data form } \\
\text { referral pada form pengisi } \\
\text { data referral setelah } \\
\text { melakukan login }\end{array}$ & $\begin{array}{l}\square \text { Berhasil } \\
\square \text { Gagal }\end{array}$ \\
\hline 5 & $\begin{array}{l}\text { Form } \\
\text { Pending } \\
\text { Muncul } \\
\text { saat login } \\
\text { sebagai } \\
\text { bank } \\
\text { consultant }\end{array}$ & $\begin{array}{l}\text { Setelah } \\
\text { karyawan } \\
\text { mengisikan data } \\
\text { referral, akan } \\
\text { muncul data } \\
\text { referral pada } \\
\text { form pending }\end{array}$ & $\begin{array}{l}\text { Dapat memunculkan data } \\
\text { yang diisi pada form } \\
\text { referral }\end{array}$ & $\begin{array}{l}\square \text { Berhasil } \\
\square \text { Gagal }\end{array}$ \\
\hline 6 & $\begin{array}{l}\text { Data } \\
\text { referral } \\
\text { muncul } \\
\text { saat data } \\
\text { berhasil di } \\
\text { closing }\end{array}$ & $\begin{array}{l}\text { Bank consultant } \\
\text { melakukan } \\
\text { closing } \\
\text { terhadap data } \\
\text { yang muncul di } \\
\text { list pending }\end{array}$ & $\begin{array}{l}\text { Data dapat pindah } \\
\text { menuju status closing }\end{array}$ & $\begin{array}{l}\square \text { Berhasil } \\
\square \text { Gagal }\end{array}$ \\
\hline 7 & $\begin{array}{l}\text { Data } \\
\text { referral } \\
\text { muncul } \\
\text { saat data } \\
\text { berhasil di } \\
\text { reject }\end{array}$ & $\begin{array}{l}\text { Bank consultant } \\
\text { melakukan } \\
\text { reject terhadap } \\
\text { data yang } \\
\text { muncul di list } \\
\text { pending }\end{array}$ & $\begin{array}{l}\text { Data dapat berubah status } \\
\text { menjadi reject }\end{array}$ & $\begin{array}{l}\square \text { Berhasil } \\
\square \text { Gagal }\end{array}$ \\
\hline
\end{tabular}

Kuesioner diberikan kepada 15 karyawan, 4 Bank Consultant dan 1 kepala cabang Bank BCA cabang Ayani Pontianak. Berikut merupakan hasil kuesioner terhadap penilaian pengunaan sistem informasi pencatatan data referral:

Tabel 2. Data Kuesioner

\begin{tabular}{|c|c|c|c|c|c|}
\hline \multirow[b]{2}{*}{ No } & \multirow[b]{2}{*}{ Pertanyaan } & \multicolumn{4}{|c|}{$\begin{array}{ll}\text { Tingkat Kepuasan } \\
\end{array}$} \\
\hline & & $\begin{array}{c}\text { Sanga } \\
\mathbf{t} \\
\text { Setuju }\end{array}$ & $\begin{array}{c}\text { Setuj } \\
\mathbf{u}\end{array}$ & $\begin{array}{l}\text { Cukup } \\
\text { Setuju }\end{array}$ & $\begin{array}{c}\text { Tidak } \\
\text { Setuj } \\
\text { u }\end{array}$ \\
\hline 1 & $\begin{array}{l}\text { Aplikasi } \\
\text { membantu } \\
\text { dalam } \\
\text { proses } \\
\text { penginputan } \\
\text { data referral }\end{array}$ & 15 & 5 & 0 & 0 \\
\hline 2 & $\begin{array}{l}\text { Aplikasi } \\
\text { sangat } \\
\text { mudah } \\
\text { digunakan }\end{array}$ & 14 & 1 & 0 & 0 \\
\hline 3 & $\begin{array}{l}\text { Aplikasi } \\
\text { sangat } \\
\text { ringan saat } \\
\text { dijalankan }\end{array}$ & 10 & 2 & 2 & 1 \\
\hline 更 & $\begin{array}{l}\text { Aplikasi } \\
\text { memberikan } \\
\text { manfaat } \\
\text { yang sangat } \\
\text { besar untuk } \\
\text { menginput } \\
\text { data referral }\end{array}$ & 13 & 2 & 0 & 0 \\
\hline 5 & $\begin{array}{l}\text { Sistem } \\
\text { diterapkan } \\
\text { pada Bank } \\
\text { BCA } \\
\text { cabang } \\
\text { Ayani } \\
\text { Pontianak }\end{array}$ & 13 & 2 & 0 & 0 \\
\hline & Berikut & meru & akan & pe & entase \\
\hline
\end{tabular}

Kuesioner berdasarkan pertanyaan yang diberikan kepada pengguna, dalam hal ini adalah 13 Karywan, 4 Bank Consultant dan 1 kepala cabang Bank BCA cabang Ayani Pontianak.

1. Aplikasi membantu dalam proses penginputan data referral

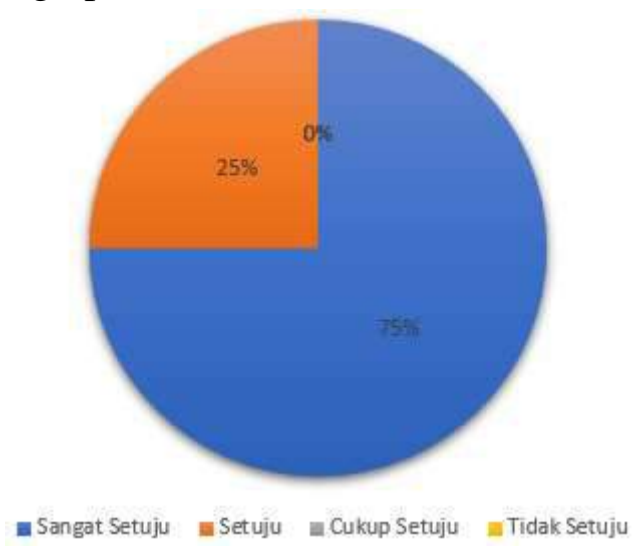

Gambar 20. Pertanyaan Point 1

2. Aplikasi sangat mudah digunakan

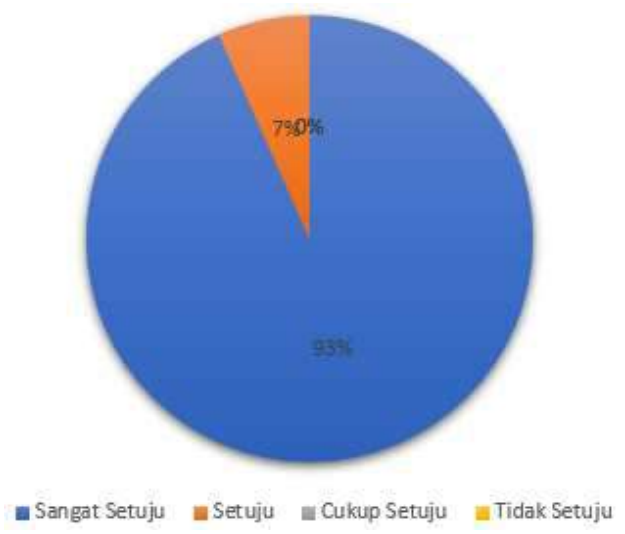

Gambar 21. Pertanyaan Point 2

3. Aplikasi sangat ringan saat dijalankan

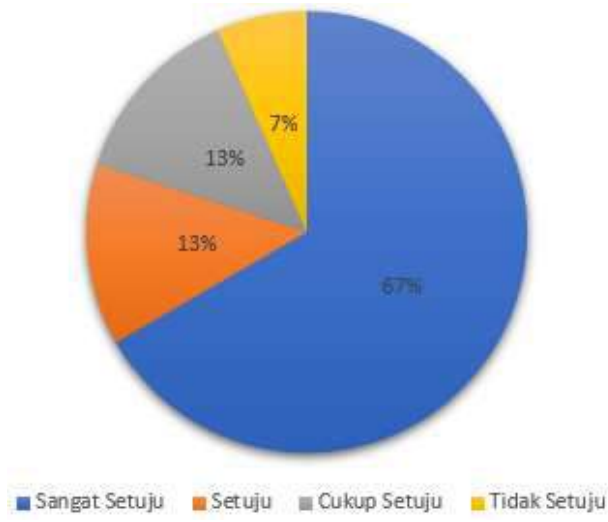

Gambar 22. Pertanyaan Point 3

4. Aplikasi memberikan manfaat yang sangat besar untuk menginput data referral 


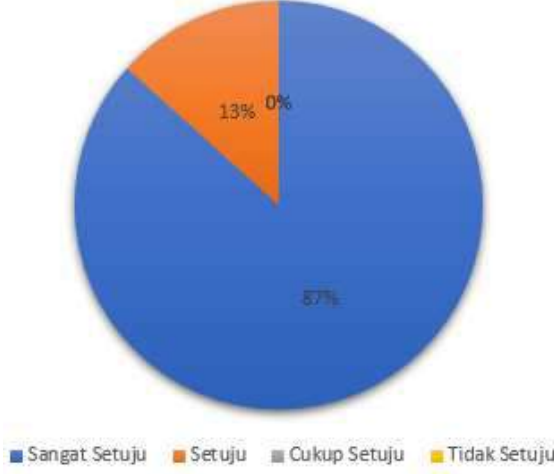

Gambar 23. Pertanyaan Point 4

5. Sistem diterapkan pada Bank BCA cabang Ayani Pontianak

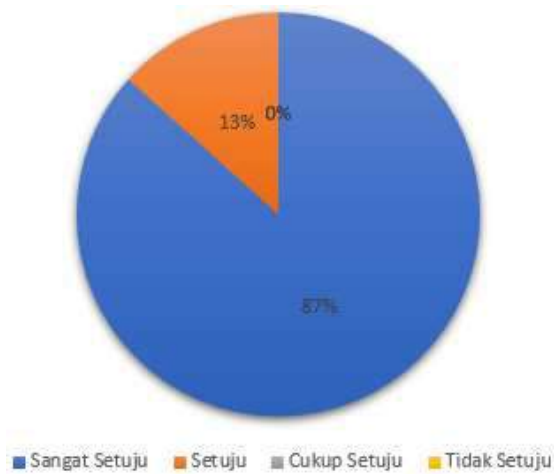

Gambar 24. Pertanyaan Point 5

\section{Kesimpulan}

Dari perancangan aplikasi pencatatan data referral untuk Bank BCA yang telah dilakukan, maka dapat disimpulkan bahwa aplikasi pencatatan data referral ini akan mempermudah pekerjaan para karyawan Bank BCA, karena sebanyak $75 \%$ peserta memberikan jawaban aplikasi membantu proses referral serta $87 \%$ setuju agar aplikasi diterapkan pada Bank BCA cabang Ayani Pontianak.

Aplikasi ini juga memiliki fleksibilitas, sehingga para karyawan Bank BCA bisa menggunakan aplikasi ini dimanapun dan kapanpun. Hal ini ditunjukan oleh 93\% responden menyatakan setuju.
Pengujian black box terhadap sistem saat dieksekusi juga menunjukkan keberhasilan aplikasi saat dijalankan.

Penerapan metodologi prototyping juga memberikan gambaran kepada pengguna bagiamana aplikasi akan dikembangkan. Dari pengujian yang dilakukan, penulis dapat melakukan peningkatan terhadap kualitas aplikasi.

\section{Saran}

Perlunya pelatihan yang diberikan kepada sumber daya manusia yang ada pada Bank BCA cabang Ayani Pontianak secara berkala.

Perlunya adanya fitur eksport data dalam bentuk Microsoft Excel.

Sistem informasi pencatatan data referral harus selalu di-update sesuai dengan perkembangan teknologi di masa yang akan datang agar sesuai perkembangan zaman sehingga menjadi semakin canggih.

\section{Daftar Pustaka}

[1] Lubis, Adyanata. Basis Data Dasar. CV Budi Utama. Yogyakarta. 2016.

[2] Wijoyo, Hadion. Ariyanto, Aris. Sudarsono, Agus. dan Wijayanti, Kiki Dwi. Sistem Informasi Manajemen. Insan Cendekia Mandiri. Sumatera Barat. 2021.

[3] Kristanto, Andri. Perancangan Sistem Informasi dan Aplikasinya. Gava Media. 2008.

[4] Hamidin, Dini. Rosita, Ai. Wibowo, Hadi. Perancangan Prototype Sistem Aplikasi Production Equipments Management (Studi Kasus di PT. Digrantara Indonesia). Jurnal Teknologi Informasi, Vol.1, No. 2, pp. 39-44, 2011.

[5] Sugiarti, "Analisis Dan Perancangan Sistem Informasi Dengan Metodologi Berorientasi Objek," Informatika, Bandung, 2013. 